\title{
Evaluation and Optimization of Urban Basic Education Facilities Layout based on GIS_A Case Study in Xuzhou, China
}

\author{
Ma Yue ${ }^{1}$, Shen Shan $^{1 *}$ \\ ${ }^{1}$ School of Geography, Geomatics, and Planning, Jiangsu Normal University, Xuzhou, 221116, China
}

\begin{abstract}
The layout of educational facilities has become a hot topic in urban geography research. Guides by rational demand consensus, typical human settlements extraction and matching of physical property planning, this paper constructs an evaluation system for the spatial layout of urban basic education facilities from the perspective of " Homo-Urbanicus " theory. The content includes the evaluation of accessibility, evaluation of bearing pressure, classification of layout types, selection and analysis of excellent communities. This paper conducts an empirical research on the basic education facilities of kindergartens, elementary schools and middle schools in the main urban area of Xuzhou City. And then, we delineated excellent community, standard communities, under-covered communities, overstressed communities, undeveloped communities on the basis of evaluation results. Finally, we selected sample communities for analysis, and put forward relevant optimization strategies.
\end{abstract}

\section{Introduction}

The equity of basic education is important to social equity as educational distribution is to man educational foundation [1,2]. Chinese Education Modernization 2035 [3] proposes to promote the high-quality and balanced development of compulsory education as well as promote the universal and beneficial development of basic education. At the same time, scientific layout of basic education facilities plays an important role in promoting high-quality urban development and improving urban quality.

Existing studies mainly focus on the accessibility of educational facilities, ethnic differences, and the spatial effect of education on communities $[4,5,6]$, etc. O'Brien [7] advocated the establishment of an educational layout system that is integrated with efficiency and equity to improve the accessibility of educational facilities. Lange [8] explored the correlation between educational layout and residential differentiation from the perspective of economics and sociology. McDonald [9] discussed the influence of school site selection and service on surrounding communities by sorting out the standards of school construction. In addition, some studies have shown that differences in the allocation of educational resources exist among different social groups. Peiyang [10] believed that differences in the allocation of educational resources lead to residential migration and class agglomeration, thus aggravating the spatial differentiation of social classes.

Based on the informed research and the actual issues of the basic educational facilities in China, we will explore several issues

(1) How to seek consensus between residents' needs and facility layout? How to consensus between residents' needs and facility layout can be coordinated, and the optimal balance interval can be found.

(2) How to accurately identify the mismatch between supply so as to demand and develop the corresponding optimal layout strategy?

(3) How to coordinate ideal choice and realistic constraints to build a stable supply-demand matching relationship of basic education facilities?

\section{The theoretical framework and methods}

\subsection{The theory of "Homo-Urbanicus"}

By referring the theory of "economic man" in the western classical economics and the theory of "human settlement science" by Doxiadis, Hok-Lin Leung put forward the theory of "Homo-Urbanicus" which is people-oriented.[11] " Homo-Urbanicus " are who rationally choose to live in clusters to pursue spatial contact, and the core of urban planning is to match typical "Homo-Urbanicus" with typical "human settlement environment".

\subsection{Research method}

Due to basic education facilities as a typical spatial contact, its layout should meet the demand of people's property and rational, this can be explained by " Homo-Urbanicus ".

2.2.1. Rational needs consensus. According to the theory of "Homo-Urbanicus", the rationality of the

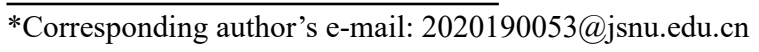


residents is embodied in "self-preservation" and "coexistence", Therefore, a rational balance between "self-existence" and "coexistence" should be sought to improve the spatial contact opportunities within the consensus range.

\subsubsection{Identification of typical layout types. The} identification of typical human settlements is an important method to analyse "Homo-Urbanicus". [11] It is more helpful to propose an optimal strategy by classifying different types of community layout through multiple variables and analyzing the causes of different types.

\subsubsection{Planning and matching of physical properties.} The match between residents and basic educational facilities is the optimization of "Accessibility" and "Bearing capacity ". The significance of planning is to enable more residents to have equal access to basic educational facilities through spatial planning and layout.

This paper firstly took the community as the evaluation unit, secondly divided the layout types of basic education facilities, again selected sample communities for layout reference and identified the mismatched communities, finally put forward optimization strategies from the evaluation of accessibility and bearing pressure.

\section{A case study of Xuzhou city}

\subsection{Research area and data}

Xuzhou is a typical resource-transformation city in China. The scope of data acquisition in this study is defined in the main urban area of Xuzhou. The data adopted in this study mainly include the spatial location data of basic education facilities POI (point of internet) in Xuzhou, the information of residents' population and spatial distribution, the current urban road network, and the policies and norms on the configuration standards of kindergartens and primary and secondary schools. POI spatial data are derived from the open platform of Amap, including the locations of kindergartens, primary schools and middle schools and their related attributes. The population data comes from the regional version of wellknown real estate websites in China, and Python crawler program is used to obtain the location and number of households of each community in the main urban area of Xuzhou. The data of community boundary and urban road network were obtained from the Laboratory of Complex and Sustainable Urban Networks (CSUN) of the University of Illinois at Chicago, USA.

\subsection{Layout evaluation of basic educational facilities}

3.2.1. The evaluation unit. In reality, due to the basic education facilities and services are often divided according to community boundaries. Therefore, this paper takes community boundaries as a unit to evaluate the layout of basic education facilities. With reference to the Standard for Planning and Design of Urban Residential Areas, the community evaluation is divided into different level, the natural discontinuity method was used to visualize each evaluation result.

3.2.2. Layout Type Partitioning. In order to effectively identify the layout characteristics of basic education facilities in different communities and put forward corresponding optimization strategies, community space of basic education facilities in Xuzhou City was summarized into 5 types based on community space boundary and overlay the results of accessibility evaluation and stress-bearing evaluation (Fig. 1). (1) Excellent community, at least one evaluation of accessibility and Bearing pressure higher than ordinary level; (2) Standard community, accessibility evaluation and facility bearing pressure evaluation are average; (3) Under-covered community, lower accessibility evaluation and above average stress evaluation of facilities; (4) Overstressed community, with an average or above level of accessibility and a lower than average level of facility bearing pressure; (5) Undeveloped community, where the evaluation of accessibility and stress of facilities are lower than the average level.

3.2.3. Results of evaluation. The superposition results showed that: (1) The comprehensive evaluation of three types of basic educational facilities in kindergarten and primary school was higher, while that in middle school is worse; (2) The comprehensive the evaluation of kindergarten is relatively high, and also showed that the current situation of urban center is under too much pressure and the marginal area is not covered enough, this meant the needs of the periphery of the city to study nearby; (3) Primary schools have the highest comprehensive evaluation among the three types of basic education facilities, but some communities located at the edge of the main urban area have under-covered and overstressed, indicating that the overall layout of kindergartens tends to the center of the urban area, and can not meet the needs of the periphery of the urban area to go to school nearby; (4) Middle school comprehensive evaluation results as a whole is low, insufficient coverage and pressure overload community is more, but, in contrast to the primary school, under-covered communities focused on the city center, overstressed communities in urban fringe, illustrate the middle school lack of overall layout, and there are more accessibility is insufficiency, the large bearing pressure and the undeveloped community. 


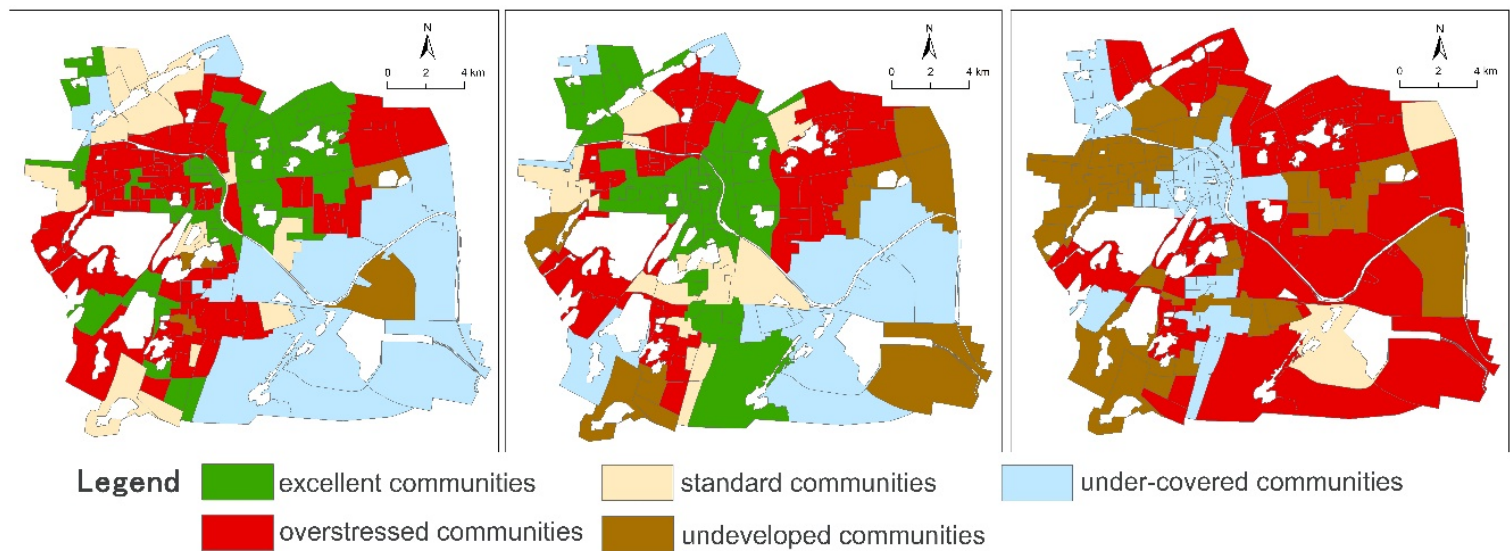

Figure 1 Distribution of community basic education facilities in the main urban area of Xuzhou

\subsection{Identification and analysis of the layout of educational communities}

This paper have selected sample communities of education layout as practical reference and normative layout demonstration. Based on the review results in the above section, this paper selects demonstrative communities and standard communities with strong representation for the three types of basic educational facilities as typical samples.

Table 1 Community evaluation results of educational layout samples

\begin{tabular}{ccccc}
\hline Case Type & Community Name & Education Facilities Type & Accessibility & $\begin{array}{c}\text { Services Population } \\
\text { (people) }\end{array}$ \\
\hline $\begin{array}{c}\text { Excellent } \\
\text { community }\end{array}$ & Wenwo Community & Kindergarten & $15 \mathrm{~min}$ & 17722 \\
\hline \multirow{2}{*}{ Standard } & Kenghuangshan Community & Kindergarten & $15 \mathrm{~min}$ & 40984 \\
Community & Jiulonghu Community & Primary School & $30 \mathrm{~min}$ & 25806 \\
& Pantao Community & Middle School & $30 \mathrm{~min}$ & 6541 \\
\hline
\end{tabular}

In the two excellent communities and the three standard communities, the average service access standards of residents for $15 \mathrm{~min}$ and $30 \mathrm{~min}$ have been reached respectively, and the facilities bear less pressure (Table1). Most of the demonstration and standard community is located in Xuzhou city central zone of the population density is bigger, development speed is relatively mature, still have to face the uncertainty of future problems, such as the aging of educational facilities and the opening of two-child policy, the issues that led to the increase in the number of the education demand should therefore dynamic monitoring population change, improve, improve education facilities configuration. Overstressed communities are partly caused by geographical conditions, but the main problem is still that the accessibility is not up to standard. Therefore, increasing the layout of educational facilities and optimizing road connectivity are the next urgent work to be completed.

\subsection{Optimization Suggestions}

\subsubsection{Combined with the needs of residents, adopt measures to upgrade the standard community.}

We need to monitor changes in population data dynamically to ensure the fairness of the spatial distribution of basic education facilities. Then we will make full use of the existing basic education facilities to optimize the structure of the existing facilities and improve the level of educational facilities and services.

\subsubsection{Accurately identify under-covered} communities and improve access to educational space. For the under-covered communities, the density of the road network can be improved, and the travel environment can be improved to increase the opportunities for spatial access to education. Improving the urban pedestrian transportation system and increasing the density of travel network can properly break the closure of communities as well as improve the accessibility of basic education facilities.

\subsubsection{Remitting the overstressed communities and} establishing the dynamic flow and sharing mechanism of educational resources. We can increase the capacity allocation of educational facilities in densely populated urban central communities to enhance the service capacity of schools through sporadic update capacity expansion and quality improvement. Then we can optimize the stock, revitalize the existing educational resources to change the situation of idle and waste of highquality educational resources. 
3.4.4. Focusing on optimizing the undeveloped communities to fill the gaps in the layout of basic education. We will increase basic educational facilities and give priority to meeting the basic educational needs of the school-age population to achieve full coverage of education.

\section{Conclusion and discussion}

This paper took the main urban area of Xuzhou City as an example to evaluate the layout of three types of basic education facilities by using the theory of "HomoUrbanicus", then classify the layout types of basic education facilities in different communities, last put forward targeted optimization strategies. The analysis results are as follows.

The accessibility of primary school is better than kindergarten and middle school, and the layout of primary school and kindergarten is significantly better than middle school. The excellent communities and the standard communities should continue to prompt the service quality as the reference samples for the education layout and development of other communities. Under-covered communities should increase the distribution of educational facilities and improve the space access opportunities. Overstressed communities should increase the capacity of education and relieve the overcrowded population. Undeveloped communities as the focus of the next education facility layout, they should be implemented as soon as possible to fill the shortage of education allocation.

This study evaluated quantitatively the layout of basic educational facilities in community space and extracted the excellent communities and standard communities with relatively perfect services. On this basis, we identified the imbalance in the development of community education layout, include under-covered communities, overstressed communities and undeveloped communities, to provide the empirical basis for decision-making and ease the education fairness. However, there are still some limitations in this study. First of all, due to the limitation of data acquisition, the scale of basic education facilities, service capacity, travel mode and other factors of the educated did not have to be considered, so there are still errors in the calculation results. Secondly, this paper lacked cause and mechanism discrimination why the distribution of basic educational facilities is unfair, and we will take community residents as the object and adopt the methods of questionnaire survey and community interview to obtain more detailed micro data, in order to obtain more scientific and reasonable research results in the future.

\section{Funding}

This research was financially supported by the Priority Academic Program Development of Jiangsu Higher Education Institutions.

\section{References}

1. Malczewski J, Jackson M. (2000) Multicriteria spatial allocation of educational resources: An overview. Socio-Economic Planning Sciences, 34 (3) :219-235.

2. Hongqi C. (2020) What Kind of Educational Equity We Need in the New Era Consummating the Domain of Research Questions and the Policy Toolbox of Educational Equity. Educational Research, 41(02):4-16.

3. CPC Central Committee, (2019) State Council. China's education modernization. http://www.gov.cn/zhengce/201902/23/content 5367987.htm.

4. Talen E. (2001) An empirical investigation of access to elementary schools in West Virginia.

5. Lenntorp B. (1978) A time-geographic simulation model of individual activity programs. Human activity and time geography vol.2.

6. Agarwal S, Rengarajan S, Sing T F, et al. (2016) School allocation rules and housing prices: A quasiexperiment with school relocation events in Singapore. Regional Science and Urban Economics, 58.

7. O'Brien. R J. (1969). Model for planning the location and size of urban schools. Socio-Economic Planning Sciences, 2(2-4), 141-153.

8. Lange W J, Koslinski M C, Alves F. (2013) Educational inequalities in urban contexts: a study of the geography of educational opportunities in the city of Rio de Janeiro. Educao \& Sociedade. 35 (125): 200-220.

9. Mcdonald, C N. (2010) School Siting: Contested Visions of the Community School. Journal of the American Planning Association, 2(76):184-198.

10. Peiyang C. (2015) School district and Its SocioSpatial Consequences in Urban China. Urban Studies, 22 (8): 55-60.

11. Hok-Lin L. (2020) Homo-Urbanicus: Basic logic and operating procedure. City Planning, 44(02):68-76. 